\title{
A 95-year-old patient with unexpected coronavirus disease 2019 masked by aspiration pneumonia: a case report
}

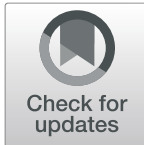

Francesco Spannella ${ }^{1,2}$, Letizia Ristori ${ }^{1,2}$, Federico Giulietti ${ }^{1,2}$, Serena Re ${ }^{1,2}$, Paola Schiavi ${ }^{1,2}$, Piero Giordano ${ }^{1}$ and Riccardo Sarzani ${ }^{1,2^{*}}$ (i)

\begin{abstract}
Background: Severe acute respiratory syndrome coronavirus-2 infection has become a pandemic disease (coronavirus disease 2019). The infection has moved from China to the rest of the world and Italy represents one of the most affected countries. Older adults are more susceptible to develop complications with the consequent highest mortality rates.

Case presentation: We report a case of a 95-year-old Caucasian woman affected by pneumonia, initially defined as common aspiration pneumonia in a bedridden patient with vascular dementia, which later turned out to be coronavirus disease 2019 pneumonia during the initial spread of severe acute respiratory syndrome coronavirus-2 in our district. Some features of a computed tomography scan of her chest and her clinical history with known dysphagia had led at first to a different diagnosis with a consequent exposure of health professionals to infectious risk in two distinct hospitals. In this case report, we describe the clinical/imaging features of coronavirus disease 2019 pneumonia and the diagnostic process that led to a correct diagnosis in a nonagenarian with multiple comorbidities.

Conclusions: This case report highlights both the possible pitfalls in diagnosing coronavirus disease 2019 pneumonia in very old patients with comorbidities and the greater than expected spread of the infection, even in individuals with reduced interpersonal contacts and no defined epidemiological link.
\end{abstract}

Keywords: SARS-CoV-2, COVID-19, Older, Elderly, Pneumonia

\section{Background}

Coronavirus disease 2019 (COVID-19), caused by severe acute respiratory syndrome coronavirus-2 (SARS-CoV2) infection, has spread globally since the first cases were described in November 2019 in Wuhan, China. Since 21 February 2020, when COVID-19 emerged in northern Italy's Lombardy region, the number of infected patients in Italy closely followed an exponential trend, with the

\footnotetext{
*Correspondence: r.sarzani@univpm.it

"Internal Medicine and Geriatrics, "Hypertension Excellence Centre" of the European Society of Hypertension, Italian National Research Centre on Aging, Hospital "U. Sestilli", IRCCS INRCA, via della Montagnola n. 81, 60127 Ancona, Italy

2Department of Clinical and Molecular Sciences, University "Politecnica delle Marche", Ancona, Italy
}

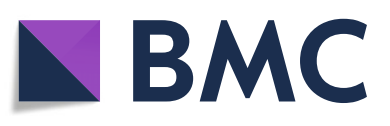

C C The Author(s). 2020 Open Access This article is licensed under a Creative Commons Attribution 4.0 International License, which permits use, sharing, adaptation, distribution and reproduction in any medium or format, as long as you give appropriate credit to the original author(s) and the source, provide a link to the Creative Commons licence, and indicate if changes were made. The images or other third party material in this article are included in the article's Creative Commons licence, unless indicated otherwise in a credit line to the material. If material is not included in the article's Creative Commons licence and your intended use is not permitted by statutory regulation or exceeds the permitted use, you will need to obtain permission directly from the copyright holder. To view a copy of this licence, visit http://creativecommons.org/licenses/by/4.0/ The Creative Commons Public Domain Dedication waiver (http://creativecommons.org/publicdomain/zero/1.0/) applies to the data made available in this article, unless otherwise stated in a credit line to the data. risk of reaching saturation point for beds in intensive care units. The higher risk of complications and death in older patients was immediately evident [1]. In a Chinese report, older patients accounted for $15.1 \%$ of the patients affected by COVID-19 and 27\% of patients with severe disease were older than 65 years [2]. The Italian National Institute of Health (Istituto Superiore di Sanità; ISS) found that $38.4 \%$ of the patients affected by COVID-19 in Italy were older than 70 years of age. Moreover, the case fatality rate increases with increasing age, reaching $32.7 \%$ for those over 80 years of age [3]. Lung injury plays a central role in the pathophysiology and symptoms of COVID-19 [4]. 
Respiratory diseases and pneumonia per se are among the major causes of hospitalization in the older population with a marked higher mortality rate compared to the adult population [5]. Aspiration pneumonia is a leading cause of pneumonia in older patients, accounting for 5 to $15 \%$ of all cases of community-acquired pneumonia [6], and it is estimated that at least $70 \%$ of hospitalized pneumonia in patients older than 70 years can be diagnosed as aspiration pneumonia [7].

In this case report, we describe the clinical/imaging features of a case of COVID-19 pneumonia, initially defined as common aspiration pneumonia, and its diagnostic process in a very old patient with comorbidities, when the SARS-CoV-2 infection was not yet widespread in Italy.

\section{Case presentation}

A 95-year-old Caucasian woman was admitted to our Internal Medicine and Geriatrics Department on 2 March 2020. Her symptoms started on 26 February 2020 with onset of fever, cough, and vomiting, which led to her hospitalization in the main general hospital of the town in which she lived, where an initial diagnosis of aspiration pneumonia was made. In the diagnostic workup, she had several comorbidities including arterial hypertension, chronic heart failure, paroxysmal atrial fibrillation, dyslipidemia, stage G4 chronic kidney disease, vascular dementia with deconditioning syndrome, sacral pressure ulcers, and known dysphagia. Home medications were the following: furosemide $25 \mathrm{mg}$, amiodarone $200 \mathrm{mg}$, warfarin $5 \mathrm{mg}$, and pantoprazole $20 \mathrm{mg}$.

She lived at home with her son and a caregiver. At initial interview, both of them denied any travel to areas of high transmission for COVID-19 or contact with people coming from these areas (there was no clear epidemiological link). She had been vaccinated for the seasonal influenza virus. She was almost totally dependent on both basic activities of daily living (BADL) and instrumental activities of daily living (IADL). On admission, she had fever $\left(39.1^{\circ} \mathrm{C}\right)$ and acute respiratory failure requiring oxygen supplementation with arterial oxygen saturation $\left(\mathrm{SaO}_{2}\right)$ of $93 \%$ with fraction of inspired oxygen $\left(\mathrm{FiO}_{2}\right)$ of $40 \%$, altered mental status, tachycardia with heart rate of 94 beats per minute (bpm), and high blood pressure $(160 / 80 \mathrm{mmHg})$. Other relevant features on physical examination were bilateral lung crackles and peripheral pitting edema. On day 1 after admission, a chest computed tomography (CT) scan was performed to better characterize the admission chest X-ray findings (bilateral patchy shadowing, Fig. 1), showing multiple bilateral ground glass opacities (GGOs), crazy-paving pattern, and bilateral lobular and sub-segmental areas of consolidation (mainly focused in lingular segment of left lung and inferior lobe of bilateral lungs) (Fig. 2). Laboratory tests on admission (Table 1) showed a normal white blood

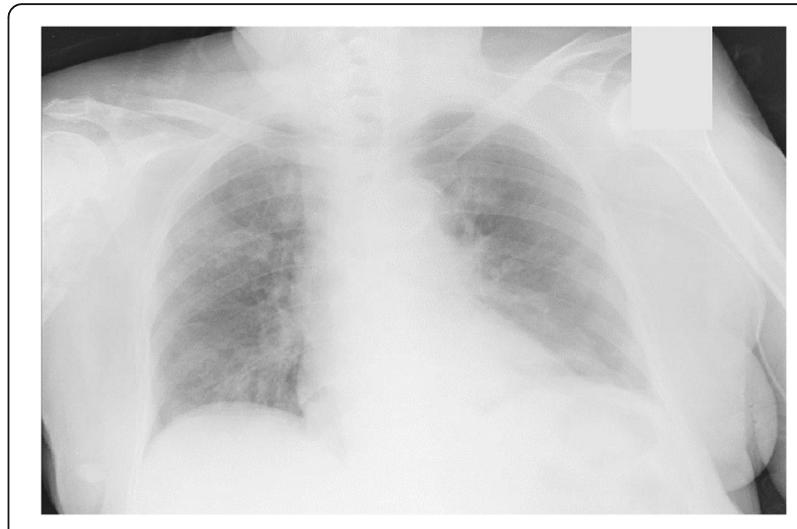

Fig. 1 Chest $X$-ray performed on admission (single supine anteroposterior view) showing bilateral patchy shadowing

cell (WBC) count with lymphopenia, high C-reactive protein, and slightly increased serum levels of procalcitonin. D-dimer and aminotransferase levels were within normal range, whereas $\mathrm{N}$-terminal pro-B natriuretic peptide (NT-proBNP) levels were elevated. Pneumococcal and Legionella urinary antigen tests were negative. Blood and urine cultures were negative. Bronchoalveolar lavage collected from our patient on admission tested positive for methicillin-sensitive Staphylococcus aureus $(10,000 \mathrm{CFU} / \mathrm{ml})$ and Citrobacter werkmanii $(100,000 \mathrm{CFU} / \mathrm{ml})$, both sensitive to piperacillin-tazobactam. Based on this information, the empiric antimicrobial therapy started on admission with piperacillin-tazobactam was maintained. A bedside swallowing assessment was also performed, confirming dysphagia to both liquids and solids. During the hospitalization, she had two episodes of high-rate atrial fibrillation $(160 \mathrm{bpm})$ treated with metoprolol and amiodarone, with restoration of sinus rhythm. After hemodynamic stabilization, she was transferred to our ward for geriatric management.

A real-time reverse transcriptase-polymerase chain reaction (rRT-PCR) assay for SARS-CoV-2 was not performed on admission, due to the lack of previous history of travels or close contact with a confirmed or probable case of COVID-19 in the previous 14 days, according to the epidemiological criteria disclosed by health authorities at that time (World Health Organization's criteria of suspicion for SARS-CoV-2 infection). However, after her admission at our ward, the persistence of severe hypoxemia, fever $\left(37.6{ }^{\circ} \mathrm{C}\right)$, cough, and high C-reactive protein $(14.68 \mathrm{mg} / \mathrm{dl})$ coupled with reduced procalcitonin $(0.14 \mathrm{ng} / \mathrm{ml})$ after appropriate antibiotic therapy, prompted us to collect nasopharyngeal and oropharyngeal swabs on 3 March 2020 even in the absence of epidemiological criteria. The rRT-PCR assay tested positive for SARS-CoV-2 infection. She was then isolated and managed by a dedicated health care team, according to the protocol of our hospital. After an initial period of clinical stability with high-flow oxygen, she required 


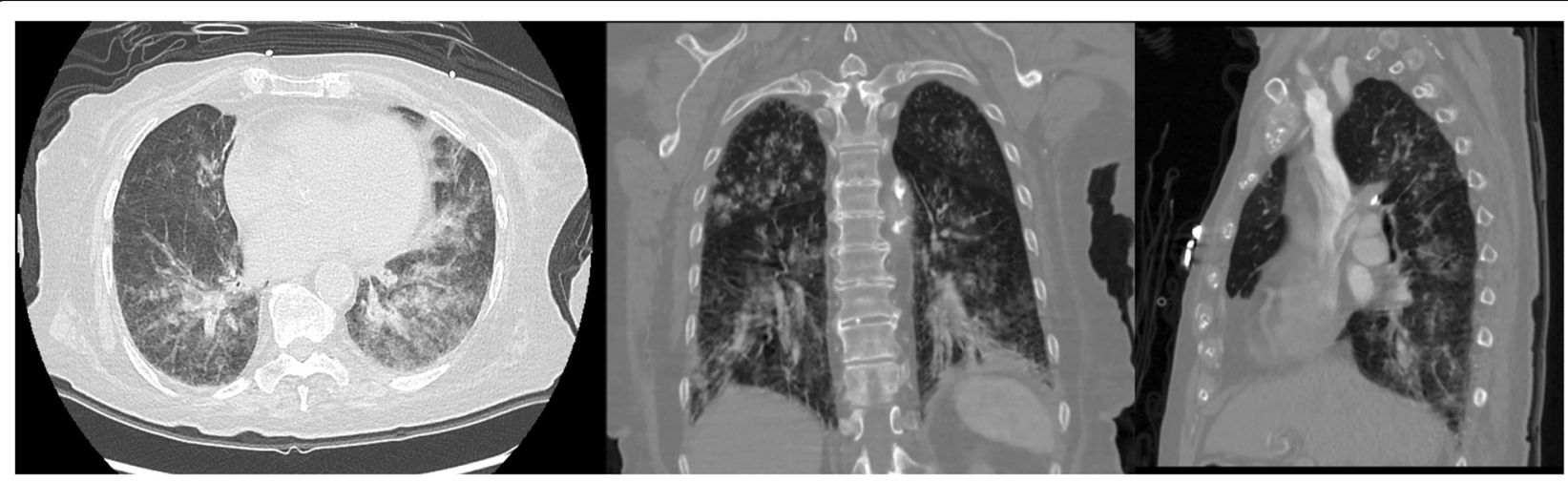

Fig. 2 Chest computed tomography performed on day 1 after admission showing multiple bilateral ground glass opacities, coupled with crazypaving pattern, as well as bilateral lobular and sub-segmental areas of consolidation. Axial view (left); coronal view (center); sagittal view (right)

Table 1 Main admission laboratory findings

\begin{tabular}{ll}
\hline Laboratory parameters & Laboratory findings \\
\hline White blood cell count & $6940 / \mathrm{mm}^{3}$ \\
Red blood cell count & $3,110,000 / \mathrm{mm}^{3}$ \\
Hemoglobin & $10.4 \mathrm{~g} / \mathrm{dl}$ \\
Hematocrit & $28.9 \%$ \\
Mean corpuscular volume & $93 \mathrm{fl}$ \\
Mean corpuscular hemoglobin & $33.4 \mathrm{pg}$ \\
Platelets count & $223,000 / \mathrm{mm}^{3}$ \\
Neutrophils & $86 \%$ \\
Lymphocytes & $8.9 \%$ \\
Monocytes & $5 \%$ \\
Eosinophils & $0 \%$ \\
Basophils & $0.1 \%$ \\
Neutrophil count & $5970 / \mathrm{mmc}$ \\
Lymphocyte count & $620 / \mathrm{mmc}$ \\
Monocyte count & $350 / \mathrm{mmc}$ \\
Eosinophil count & $0 / \mathrm{mmc}$ \\
Basophil count & $1 / \mathrm{mmc}$ \\
Erythrocyte sedimentation rate & $27 \mathrm{~mm} / \mathrm{hour}$ \\
Urea & $53 \mathrm{mg} / \mathrm{dl}$ \\
Creatinine & $1.14 \mathrm{mg} / \mathrm{dl}$ \\
Sodium & $133 \mathrm{mEq} / \mathrm{l}$ \\
Potassium & $4.1 \mathrm{mEq} / \mathrm{l}$ \\
N-terminal pro-B natriuretic peptide & $3576 \mathrm{pg} / \mathrm{ml}^{2}$ \\
C-reactive protein & $15.3 \mathrm{mg} / \mathrm{dl}$ \\
Pro-calcitonin & $1.04 \mathrm{ng} / \mathrm{ml}$ \\
D-dimer & $672 \mathrm{ng} / \mathrm{ml}$ \\
Aspartate aminotransferase & $17 \mathrm{U} / \mathrm{l}$ \\
\hline & $35 \mathrm{U} / \mathrm{l}$ \\
Creatine kinase & $0.107 \mathrm{ng} / \mathrm{ml}$ \\
\hline
\end{tabular}

continuous positive airway pressure in order to maintain adequate oxygenation. On 25 March 2020 she died of cardiac complications.

\section{Discussion and conclusions}

We described a case of a 95-year-old woman with several pre-existing comorbidities who was affected by COVID-19 pneumonia masked by aspiration pneumonia. If we were not in a SARS-CoV-2 pandemic, this would have been a classic case of aspiration pneumonia in a patient with vascular dementia and dysphagia. However, it turned out to be a case of COVID-19 pneumonia after the initial diagnosis. In our opinion, this case report highlights several important aspects of COVID-19.

On 2 March 2020, the date of admission to our ward, 1835 individuals had tested positive for SARS-CoV-2 at rRT-PCR assay in Italy, almost all concentrated in the Lombardy region, and only 35 cases had been tested positive in our smaller region (Marche), mainly in the northern part and not in our city [8]. Our patient was a bedridden older individual with very limited social contacts, who lived at home with her son and a caregiver who did not report any epidemiological link. Both individuals were asymptomatic. These findings probably indicate that SARS-CoV-2 had been circulating within the Italian population for some time previously, and they support the hypothesis that the virus was spreading undetected, probably through asymptomatic people. There is evidence that SARS-CoV-2 transmission can occur from asymptomatic or mildly symptomatic individuals $[9,10]$. Some authors, using a model inference framework, estimated that $86 \%$ of all infections in China were undocumented prior to the travel restrictions of 23 January 2020, suggesting that undocumented infections might have been the source for $79 \%$ of documented cases [11]. This hypothesis could also be true for Italy. Findings from a population study in Vo' Euganeo (Veneto region, Italy) showed that the majority of people infected 
with SARS-CoV-2 (50-75\%) were asymptomatic, probably representing "a formidable source" of contagion [12].

Retrospective studies on Chinese patients hospitalized for COVID-19 showed that the disease has different features in older patients. In fact, they had higher disease severity compared to young and middle-aged patients, with higher Pneumonia Severity Index (PSI) score, higher proportion of multiple lobe involvement, higher C-reactive protein, and lower lymphocytes count [13]. Symptoms at onset of COVID-19 disease often include cough, dyspnea, and fever or measured temperature $\geq$ $38^{\circ} \mathrm{C}$. However, many older patients with pneumonia often exhibit atypical symptoms and signs compared to adults [14]. Older patients with pneumonia are often afebrile, with normal WBC count, while acute changes in functional and mental status are highly prevalent. Dyspnea could also be difficult to assess, given the limited physical activity of these individuals [14]. Given the possible atypical presentations, the diagnosis of pneumonia in older patients may be challenging. In a viral pandemic era, the clinical picture may be even more complicated. In our case, the diagnosis of aspiration pneumonia was supported by the presence of dysphagia, elevated C-reactive protein, and the findings at bronchoalveolar lavage. On the other hand, some other typical laboratory parameters of COVID-19 were also present, such as the increase in Creactive protein-to-procalcitonin ratio, and absolute lymphopenia with normal WBC count [15]. However, these parameters in older patients may be difficult to interpret. For example, lymphopenia is very common in hospitalized older patients, representing a typical laboratory marker of frailty [16].

Radiographic findings of aspiration pneumonia include infiltrates in gravity-dependent lung segments (superior lower lobe or posterior upper lobe segments, if the patient is in a supine position during the event, or basal segments of the lower lobe, if the patient is upright during the event) [6]. On the other hand, GGOs and bilateral patchy shadowing, mainly in the lower lobes, are the most common patterns on chest $\mathrm{CT}$ in patients with COVID-19 [2, 17]. In fact, these CT abnormalities, not typically correlated to a diagnosis of aspiration pneumonia, were found in our case. The chest CT findings (multiple bilateral GGOs coupled with crazy-paving pattern and areas of consolidation) indicated that the COVID-19 had been present for at least approximately 5-7 days before the examination [18]. However, at that time, the experience of radiologists in interpreting and detecting COVID-19 pneumonia may have been limited by the absence of COVID-19 pneumonia spreading in our district. Furthermore, the interpretation of radiological findings can be complex in older patients [19]. In fact, a chest X-ray is often inconclusive in older patients with suspected acute lower respiratory infection [20]. At the same time, it could be difficult, even at a CT scan, to recognize the suspected pulmonary disease in the midst of the age-related changes of lung parenchyma and the several comorbidities that act as confounders [19]. For example, GGOs, a typical feature of COVID-19, have not been linked to age-related changes, but may be found in congestive heart failure, a very common condition in hospitalized older patients [21]. Our patient had high NTproBNP levels on admission, indicative of decompensated heart failure. This finding is highly prevalent in older patients admitted for lung and other infections, but without an admission diagnosis of heart failure, and it predicts in-hospital mortality $[21,22]$. The pro-calcitonin levels on admission $(>0.25 \mathrm{ng} / \mathrm{ml})$ and the results of bronchoalveolar lavage probably indicated a bacterial infection [23], which further complicated the radiological picture of chest CT in our patient. The clinical picture may be further complicated by the low sensitivity of the rRT-PCR assay for SARS-CoV-2 tested by nasopharyngeal and oropharyngeal swabs [24].

During hospitalization, two paroxysms of high-rate atrial fibrillation occurred, which is a negative prognostic factor in COVID-19, together with both high NT-proBNP and troponin I levels [25]. This testifies how viral infection can worsen stable cardiovascular comorbidities, although direct myocardial damage due to SARS-CoV-2 has also been documented [26, 27]. Pre-existing conditions, especially cardiovascular and kidney diseases, are more prevalent in older patients with severe COVID-19 compared to patients with milder disease $[2,28]$. These patients often die due to the worsening of these pre-existing conditions after the SARS-CoV-2 infection, resulting in multiple organ failure, just like other severe infections. The mortality rate of patients with acute kidney injury and COVID-19 illness is four times higher than in patients who do not have acute kidney injury [29]. Our patient had decompensated heart failure and died due to cardiac complications. There is still no consensus on the management of decompensated heart failure in older patients, particularly if affected by COVID-19. However, renin-angiotensin-aldosterone system blockers have been associated with lower inhospital mortality in older patients admitted for medical conditions [30] and these drugs are also likely to be useful in the context of the COVID-19 pandemic [31]. Therefore, it is essential to evaluate carefully and treat comorbidities appropriately in patients with COVID-19, especially if older [32].

In conclusion, this case report highlights how the diagnosis of COVID-19 pneumonia could be challenging in comorbid older patients, given the possible atypical presentation and the overlapping of other acute and chronic conditions that may complicate the interpretation of clinical, radiological, and laboratory findings. Not least, this case report shows that probably there were undocumented cases of infections with a wider spread of the virus before we became aware of it. 


\section{Abbreviations}

SARS-CoV-2: Severe acute respiratory syndrome coronavirus-2; COVID19: Coronavirus disease 2019; BADL: Basic activities of daily living; bpm : Beats per minute; IADL: Instrumental activities of daily living; ISS: Italian National Institute of Health; CT: Computed tomography; GGOs: Ground glass opacities; WBC: White blood cell; NT-proBNP: N-terminal pro-B natriuretic peptide; rRT-PCR: Real-time reverse transcriptase-polymerase chain reaction; PSI: Pneumonia Severity Index; $\mathrm{FiO}_{2}$ : Fraction of inspired oxygen; $\mathrm{SaO}_{2}$ : Arterial oxygen saturation

\section{Acknowledgements}

None.

\section{Authors' contributions}

FS and RS have made substantial contributions to the conception of the work; FS and FG have made substantial contributions to the design of the work; LR, SR, and PS have made substantial contributions to the acquisition of data; FS, FG, PG, and RS have made substantial contributions to interpretation of data; FS, LR, FG, SR, and RS have drafted the work or substantively revised it. All authors read and approved the final manuscript.

\section{Funding}

None.

\section{Availability of data and materials}

The dataset used during the current study is available from the corresponding author on reasonable request.

\section{Ethics approval and consent to participate}

Ethics committee: Comitato Etico Regionale delle Marche (CERM), 27 January 2016. N. 20150524 IN

\section{Consent for publication}

Written informed consent was obtained from the legal guardian of the patient for publication of this case report and any accompanying images. A copy of the written consent is available for review by the Editor-in-Chief of this journal.

\section{Competing interests}

The authors declare that they have no competing interests.

Received: 13 April 2020 Accepted: 2 June 2020

Published online: 23 June 2020

\section{References}

1. Garnier-Crussard A, Forestier E, Gilbert T, Krolak-Salmon P. Novel coronavirus (COVID-19) epidemic: what are the risks for older patients? J Am Geriatr Soc. 2020; https://doi.org/10.1111/jgs.16407.

2. Guan WJ, Ni ZY, Hu Y, Liang WH, Ou CQ, He JX, et al. Clinical characteristics of coronavirus disease 2019 in China. N Engl J Med. 2020;382:1708-20.

3. Istituto Superiore di Sanità (Epicentro ISS). https://www.epicentro.iss.it/en/ coronavirus/bollettino/Infografica_10giugno\%20ENG.pdf. Accessed 15 June 2020.

4. Xu Z, Shi L, Wang Y, Zhang J, Huang L, Zhang C, et al. Pathological findings of COVID-19 associated with acute respiratory distress syndrome. Lancet Respir Med. 2020;8:420-2.

5. Teramoto S, Yamamoto H, Yamaguchi Y, Hanaoka Y, Ishii M, Hibi S, et al. Lower respiratory tract infection outcomes are predicted better by an age $>80$ years than by CURB-65. Eur Respir J. 2008;31(2):477-8. author reply 8.

6. Mandell LA, Niederman MS. Aspiration pneumonia. N Engl J Med. 2019; 380(7):651-63.

7. Teramoto S, Fukuchi Y, Sasaki H, Sato K, Sekizawa K, Matsuse T, et al. High incidence of aspiration pneumonia in community- and hospital-acquired pneumonia in hospitalized patients: a multicenter, prospective study in Japan. J Am Geriatr Soc. 2008;56(3):577-9.

8. Ministero della Salute. http://www.salute.gov.it/portale/news/p3_2_1_1_1. jsp?lingua=italiano\&menu=notizie\& $\mathrm{p}=$ dalministero\&id=4142. Accessed 15 June2020.
9. Bai $Y$, Yao L, Wei T, Tian F, Jin DY, Chen L, et al. Presumed asymptomatic carrier transmission of COVID-19. JAMA. 2020;323:1406-7.

10. Rothe C, Schunk M, Sothmann P, Bretzel G, Froeschl G, Wallrauch C, et al. Transmission of 2019-nCoV Infection from an asymptomatic contact in Germany. N Engl J Med. 2020;382(10):970-1.

11. Li R, Pei S, Chen B, Song Y, Zhang T, Yang W, et al. Substantial undocumented infection facilitates the rapid dissemination of novel coronavirus (SARS-CoV2). Science. 2020;368:468-93.

12. Day M. Covid-19: identifying and isolating asymptomatic people helped eliminate virus in Italian village. BMJ. 2020;368:m1165.

13. Liu K, Chen Y, Lin R, Han K. Clinical features of COVID-19 in elderly patients: A comparison with young and middle-aged patients. J Infect. 2020;80:e14-8.

14. Faverio P, Aliberti S, Bellelli G, Suigo G, Lonni S, Pesci A, et al. The management of community-acquired pneumonia in the elderly. Eur J Intern Med. 2014:25(4):312-9.

15. Lippi G, Plebani M. Laboratory abnormalities in patients with COVID2019 infection. Clin Chem Lab Med. 2020; https://doi.org/10.1515/cclm2020-0198.

16. Rockwood K, McMillan M, Mitnitski A, Howlett SE. A frailty index based on common laboratory tests in comparison with a clinical frailty index for older adults in long-term care facilities. J Am Med Dir Assoc. 2015;16(10):842-7.

17. Salehi S, Abedi A, Balakrishnan S, Gholamrezanezhad A. Coronavirus disease 2019 (COVID-19): a systematic review of imaging findings in 919 patients. AJR Am J Roentgenol. 2020;215:1-7.

18. Bernheim A, Mei X, Huang M, Yang Y, Fayad ZA, Zhang $N$, et al. Chest CT findings in coronavirus disease-19 (COVID-19): relationship to duration of infection. Radiology. 2020;295(3):200463.

19. Gossner J, Nau R. Geriatric chest imaging: when and how to image the elderly lung, age-related changes, and common pathologies. Radiol Res Pract. 2013;2013:584793.

20. Park JE, Kim Y, Lee SW, Shim SS, Lee JK, Lee JH. The usefulness of low-dose CT scan in elderly patients with suspected acute lower respiratory infection in the emergency room. Br J Radiol. 2016;89(1060):20150654.

21. Sarzani R, Spannella F, Giulietti F, Fedecostante M, Giordano P, Gattafoni P, et al. NT-proBNP and its correlation with in-hospital mortality in the very elderly without an admission diagnosis of heart failure. PLoS One. 2016; 11(4):e0153759.

22. Spannella F, Giulietti F, Cocci G, Landi L, Lombardi FE, Borioni E, et al. Acute exacerbation of chronic obstructive pulmonary disease in oldest adults: predictors of in-hospital mortality and need for post-acute care. J Am Med Dir Assoc. 2019;20(7):893-8

23. Lee CC, Chang JC, Mao XW, Hsu WT, Chen SY, Chen YC, et al. Combining procalcitonin and rapid multiplex respiratory virus testing for antibiotic stewardship in older adult patients with severe acute respiratory infection. J Am Med Dir Assoc. 2020;21(1):62-7.

24. Wang W, Xu Y, Gao R, Lu R, Han K, Wu G, et al. Detection of SARS-CoV-2 in different types of clinical specimens. JAMA. 2020;323:1843-4.

25. Zhou F, Yu T, Du R, Fan G, Liu Y, Liu Z, et al. Clinical course and risk factors for mortality of adult inpatients with COVID-19 in Wuhan, China: a retrospective cohort study. Lancet. 2020;395(10229):1054-62.

26. Inciardi RM, Lupi L, Zaccone G, Italia L, Raffo M, Tomasoni D, et al. Cardiac involvement in a patient with coronavirus disease 2019 (COVID-19). JAMA Cardiol. 2020; https://doi.org/10.1001/jamacardio.2020.1096.

27. Clerkin KJ, Fried JA, Raikhelkar J, Sayer G, Griffin JM, Masoumi A, et al. Coronavirus disease 2019 (COVID-19) and cardiovascular disease. Circulation. 2020;141:1648-55

28. Wang D, Hu B, Hu C, Zhu F, Liu X, Zhang J, et al. Clinical characteristics of 138 hospitalized patients with 2019 novel coronavirus-infected pneumonia in Wuhan, China. JAMA. 2020:323:1061-9.

29. Ali H, Daoud A, Mohamed MM, Salim SA, Yessayan L, Baharani J, et al. Survival rate in acute kidney injury superimposed COVID-19 patients: a systematic review and meta-analysis. Ren Fail. 2020;42(1):393-7.

30. Spannella F, Giulietti F, Balietti P, Cocci G, Landi L, Lombardi FE, et al. Reninangiotensin system blockers and statins are associated with lower inhospital mortality in very elderly hypertensives. J Am Med Dir Assoc. 2018; 19(4):342-7.

31. Sarzani R, Giulietti F, Pentima CD, Giordano P, Spannella F. Severe acute respiratory syndrome coronavirus 2 infection, angiotensin-converting enzyme 2 and treatment with angiotensin-converting enzyme inhibitors or 
angiotensin II type 1 receptor blockers. Eur J Prev Cardiol. 2020: 2047487320918421. https://doi.org/10.1177/2047487320918421.

32. Wang T, Du Z, Zhu F, Cao Z, An Y, Gao Y, et al. Comorbidities and multi-organ injuries in the treatment of COVID-19. Lancet. 2020; 395(10228):e52.

\section{Publisher's Note}

Springer Nature remains neutral with regard to jurisdictional claims in published maps and institutional affiliations.

Ready to submit your research? Choose BMC and benefit from:

- fast, convenient online submission

- thorough peer review by experienced researchers in your field

- rapid publication on acceptance

- support for research data, including large and complex data types

- gold Open Access which fosters wider collaboration and increased citations

- maximum visibility for your research: over $100 \mathrm{M}$ website views per year

At $B M C$, research is always in progress.

Learn more biomedcentral.com/submissions 